\title{
Review Article \\ Role of Candidate Genes Regulating Uterine Prostaglandins Biosynthesis for Maternal Recognition of Pregnancy in Domestic Animals
}

\author{
Rohit Kumar, ${ }^{1,2}$ P. W. Ramteke, ${ }^{1}$ Amar Nath, ${ }^{3}$ R. Kumar Pramod, ${ }^{2}$ Satyendra P. Singh, ${ }^{4}$ \\ Sanjeev Kumar Sharma, ${ }^{2}$ and Sandeep Kumar ${ }^{5}$ \\ ${ }^{1}$ Sam Higginbottom Institute of Agriculture, Technology \& Sciences, Allahabad 211007, India \\ ${ }^{2}$ Animal Genetics Division, Indian Veterinary Research Institute, Izatnagar, Bareilly 243122, India \\ ${ }^{3}$ Division of Surgery, Indian Veterinary Research Institute, Izatnagar, Bareilly 243122, India \\ ${ }^{4}$ Department of Animal Genetics and Breeding, College of Veterinary Science and Animal Husbandry, DUVASU, \\ Mathura 281001, India \\ ${ }^{5}$ Animal Nutrition Division, Indian Veterinary Research Institute, Izatnagar, Bareilly 243122, India
}

Correspondence should be addressed to Rohit Kumar; rohit2005biotec@gmail.com

Received 24 March 2013; Accepted 19 April 2013

Academic Editors: A. T. Grazul-Bilska, K. Shirasuna, and D. Xiao

Copyright (C) 2013 Rohit Kumar et al. This is an open access article distributed under the Creative Commons Attribution License, which permits unrestricted use, distribution, and reproduction in any medium, provided the original work is properly cited.

\begin{abstract}
The survivability and opportunity of successful development of an embryo are influenced directly or indirectly by factors controlling uterine microenvironment. Out of all factors, hormones such as prostaglandins (PGs) released during the preimplantation period influence molecular interactions involved in maintenance of pregnancy through reciprocal interactions between the conceptus and endometrium. PGs are important regulators of female reproductive functions, namely, ovulation, uterine receptivity, implantation, and parturition. Among different classes of PGs, prostaglandin F2 $\alpha$ (PGF2 $\alpha$ ) and prostaglandin E2 (PGE2) are main prostanoids produced by human and bovine endometrium for successful growth and development of the posthatching blastocyst. In ruminants, PGF2 $\alpha$ produced by endometrium is the major luteolytic agent, whereas PGE2 has luteoprotective and antiluteolytic properties. Therefore, the development and maintenance of the corpus luteum (CL), as well as establishment of pregnancy, depend on the balance of luteolytic PGF2 $\alpha$ and luteotropic PGE2. In this review, we discussed the expression and function of genes which predominantly regulate the synthesis and their secretion of PGF2 $\alpha$ and PGES, namely, PGFS (AKR1B5/AKR1C3), PGES, PGFR, and COX-2.
\end{abstract}

\section{Introduction}

Successful embryo development and survival include formation of blastocyst, implantation into the uterus, formation of placenta, development of the heart, and vascularisation of both embryo and fetus to assist nutrient deliverance [1]. Among these developmental events, implantation of embryo is a crucial step and its success mostly depends on the efficiency with which the maternal recognition of pregnancy (MRP) is established [2,3]. The MRP includes series of events that are synchronized by the endocrine interaction between the mother and the embryo.
The majority of studies examining the molecular mechanisms of conceptus-endometrial interactions carried out during the peri-implantation period of pregnancy have focused on the maternal side, describing changes in the transcriptome of the endometrium $[4,5]$. Major factor affecting gene expression in the endometrium is day of the estrous cycle/early pregnancy. In other words, irrespective of pregnancy status, the temporal changes in gene expression in the endometrium are similar in pregnant and cyclic animals up to the time of MRP $[5,6]$.

The survivability and opportunity of successful development of an embryo are influenced directly and indirectly by 


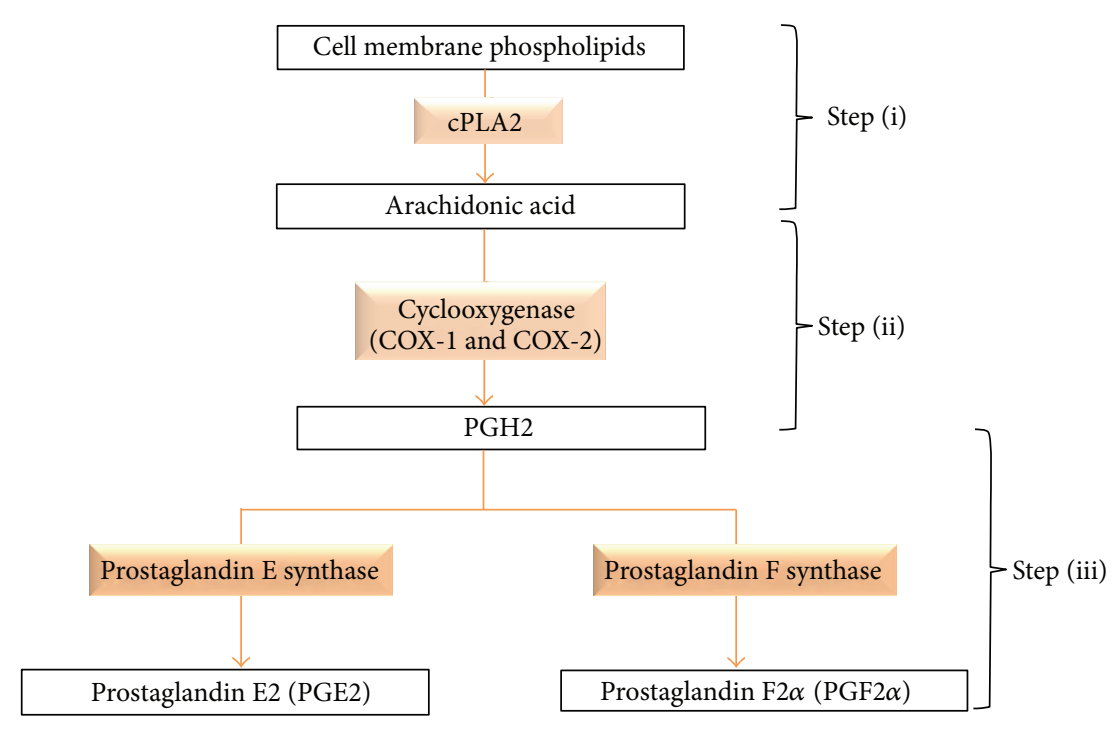

FIGURE 1: Selective representation for production of PGE2 and PGF2 $\alpha$. Steps involved (i) release of arachidonic acid (AA) from plasma membrane phospholipids through cytosolic phospholipase A2 (cPLA2). (ii) Conversion of AA into PGH2, the common precursor for all PGs, occurs through PGH synthase/COX, for which there are two isoforms COX-1 and COX-2. (iii) Conversion of PGH2 into active PG by terminal synthase PGES and PGFS.

various paracrine and autocrine factors (steroid hormones, growth factors, and cytokines), controlling uterine microenvironment [7]. Out of these factors, hormones such as PGF $2 \alpha$, PGE2 released during the preimplantation period influence molecular interactions involved in maintenance of pregnancy through reciprocal interactions between the conceptus and endometrium [8]. Proteome and transcriptome studies have revealed quantitative and qualitative changes in the genes at different stages of the estrous cycle and pregnancy [8-12]. These spatial and temporal changes were mainly due to the expression pattern of sets of genes in the uterine environment, where the endometrium is especially important for the embryo-maternal interaction and successful establishment of pregnancy. A number of important candidate genes have been identified, which regulate estrous cycle through PGF2 $\alpha$ and PGE2 production, namely, AKR1B5, PGFS, PGFR, PGES, and COX-2.

In ruminants, endometrial prostaglandins (PGs) are important regulators of estrous cycles, uterine receptivity, implantation, and parturition [13]. Two types of PGs, namely, PGF $2 \alpha$ and PGE2 are known to induce opposite effects in tissues such as kidney (human), vascular system (human), uterine myometrium (pig, cow), and corpus luteum (CL) (pig) [13]. In ruminants, PGF2 $\alpha$ and PGE2 are the primary PGs produced in the uterine endometrium, but their secretory patterns are different $[14,15]$. In ruminants, PGF $2 \alpha$ of uterine origin is responsible for luteolysis, and high levels of PGF $2 \alpha$ can disturb pregnancy at any time in several species (namely human horse pig, sheep, and cow) [16]. Luteolysis, defined as functional and/or structural regression of CL, is a key process in ovarian cycle $[17,18]$. In domestic species, luteolysis must be initiated to permit a new ovarian cycle to begin when conception does not occur. Conversely, the function and integrity of CL are required to establish and maintain pregnancy. The conceptus must therefore somehow abrogate luteolysis, a process commonly referred to as the MRP $[17,18]$. In contrast to PGES, PGE2 induces systematic effects and acts as a luteotrophic or antiluteolytic agent [19]. PGE2 also exerts an immunomodulation that helps prevent rejection of the conceptus [20]. The PGE2/PGF $2 \alpha$ ratio affects CL function, endometrial cell growth and differentiation, blood flow, vascular permeability, embryo migration, and implantation [21].

PGs are produced in response to a variety of physiological and pathological stimuli that activate phospholipase A2, resulting in the hydrolytic release of arachidonic acid (AA) from membrane phospholipids [22-25]. AA is then metabolized to the unstable cyclic endoperoxide $\mathrm{PGH} 2$ by the cyclooxygenase enzymes COX-1 and COX-2 (also known as prostaglandin $\mathrm{G} / \mathrm{H}$ synthases PGHS-1 and PGHS-2). In cows and sheep, endometrial COX-2 expression was found to be transiently induced during late diestrus around the expected time of luteolysis, whereas COX-1 expression was found to be invariant (in sheep) or undetectable (in cows) throughout the estrous cycle $[26,27]$. Therefore, cyclooxygenase (COX) is the rate-limiting enzyme that catalyses the initial step in prostaglandins (PGs) production [28].

\section{Biosynthetic Pathway of PGF2 $\alpha$ and PGE2}

PGs are synthesized in the cell from the essential fatty acids. PGH2, the common precursor of all PGs, is generated from AA by prostaglandin synthase/cyclooxygenase (PGHS/COX). However, AA is created from membrane phospholipids (phospholipase-A2) in the presence of cytosolic phospholipase A2 (cPLA2) [29]. AA is then metabolized to the unstable cyclic endoperoxide PGH2 by the COX-1 and COX-2 enzymes (Figure 1). Therefore, COX is an enzyme 
that is responsible for the formation of PGs. There are two isoforms encoded by distinct genes [30]: the constitutive isoform, COX-1, is widely expressed in a variety of tissues and cells, whereas the inducible form, COX-2, is regulated by factors such as cytokines or tumor promoters [31]. COX1 is constitutively expressed in most tissues and responsible for housekeeping functions and immediate response to levels of AA above $10 \mu \mathrm{M}$. COX-2 is regulated by factors such as cytokines or tumour promoters and supports sustained production of PGs from relatively low levels of AA (below $2.5 \mu \mathrm{M}$ ) [32]. PGH2 produced by COXs is the common precursor for generation of primary PGs including PGE2, PGF2 $\alpha$, by cell-specific isomerases and synthases (such as PGES for PGE2 and PGFS for PGF $2 \alpha$ ). The downstream enzymes, PGE synthase (PGES) and PGF synthase (PGFS), catalyze the conversion of PGH2 to PGE2 and PGF2 $\alpha$, respectively.

Among the different PGs, PGE2 and PGF2 $\alpha$ are the main prostanoids produced in the human $[33,34]$ and bovine [35] endometrium. The physiological importance of PGs in reproduction has been confirmed in the mouse, where targeted disruption of COX-1 or COX-2 genes reduced reproductive efficiency [36-38]. Null mutation for CPLA2, a PG biosynthesis enzyme upstream of COX-2, also leads to an infertile phenotype [39]. COX is the rate-limiting enzyme that catalyses the initial step in prostaglandins production [28]. At the receptor level, deletion of the PGF $2 \alpha$ receptor (PGFR) showed that it is necessary for parturition in the mouse [40]. Here, we review the genes responsible for regulation and maintenance of estrus cycle through PGs production.

2.1. Prostaglandin F2 $\alpha$ (AKR1C3 and AKR1B5). Among different classes of PGs, PGF $2 \alpha$ is one of the main prostanoids produced by bovine endometrium [35]. In ruminants, it regulates ovarian cycle through initiating the regression (luteolysis) of CL and functions as major luteolytic agent [17, 41]. In particular, PGF $2 \alpha$ is involved in labor and luteolysis to initiate a new estrous cycle in many species. Apart from sex steroids, prostaglandins are probably the most important regulators of female reproductive function (ovulation, uterine receptivity, implantation, and parturition) and associated pathologies [42]. PGF2 $\alpha$ can be produced from three distinct pathways (Figure 2). The major route in the formation PGF $2 \alpha$ is via reduction of $\mathrm{PGH} 2$ by 9,11 -endoperoxide reductase activity, referred to as PGF $2 \alpha$-synthetase (PGSF). PGFS, a monomeric enzyme, catalyzes the conversion of PGH2 to PGF2 $\alpha$. PGFS expression has been demonstrated in several tissues, namely, uterus [43], placenta [44], CL [41], lungs [45], and liver [46].

Several PGFS have been identified; three were isolated in the bovine: lung type prostaglandin F synthase (PGFS1) [45], lung type PGFS found in liver (PGFS2) [46], and liver type PGFS, also called dihydrodiol dehydrogenase 3 (DDBX) $[47,48]$. Others were also identified, respectively, in human (AKR1C3) [49], sheep [50], Trypanosoma brucei [51], and recently in the porcine endometrium [52].

All recognized mammalian PGFSs belong to the aldoketoreductase (AKR) 1C family and are generally associated

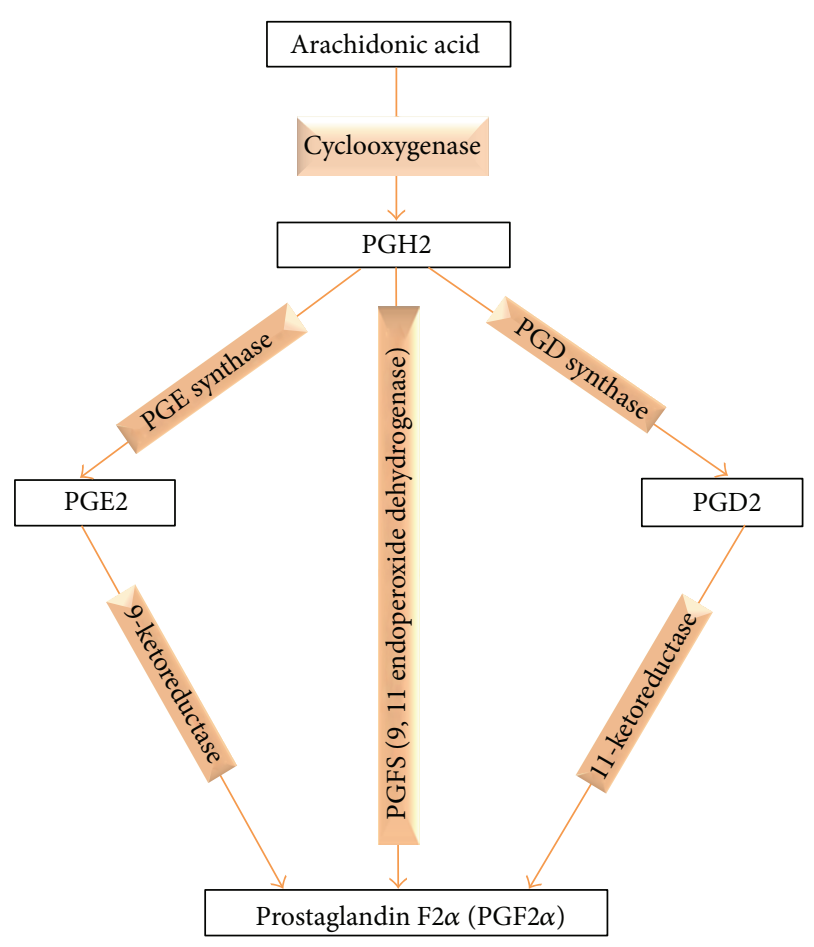

FIgURE 2: Known biosynthetic pathways leading to the formation of PGF2 $\alpha$.

with hydroxysteroid dehydrogenase (HSD) activity [29]. The members of AKR1C3 play an important role in biosynthesis of PGs, catalyzing the formation of PGF $2 \alpha$ and $9 \alpha-, 11 \beta$-PGF $2 \alpha$ from PGH2 and PGD2, respectively [63]. However, none of known functional PGFSfrom AKR1Cfamily was detected in bovine endometrium, while the expression of PGF $2 \alpha$ was very high [35].

Aldoketoreductase 1B5 (AKR1B5) was the most likely PGFS involved in the production of PGF $2 \alpha$ in bovine endometrium at the time of luteolysis [35]. Interestingly, with its $20 \alpha \mathrm{HSD}$ activity, this enzyme can also inactivate progesterone, another factor regulating endometrial function. Therefore, AKR1B5, an old enzyme, established with a new function, as a functional PGFS [35]. The human equivalent of the bovine AKR1B5 is AKR1B1 belonging to the AKR superfamily [64]. AKR1B1 also known as the aldose reductase is highly expressed in the placenta for glucose metabolism and in the eye and kidney for osmotic regulation [65]. Recently, Chapdelaine et al. [66] accumulated several lines of evidence supporting the hypothesis that AKR1B1 is a functional PGFS in the human endometrium. Kang et al. [67] demonstrated AKR1B1 association with PGF $2 \alpha$ production in human endometrial cell lines and in decidualized stromal cells. In a cell free system, purified AKR1B1 recombinant protein is able to produce PGF $2 \alpha$ from PGH2. Endometrial cell lines transiently transfected with an expression vector coding for AKR1B1 exhibit increased ability to release PGF2 $\alpha$. In contrast, when AKR1B1 expression is knockdown with specific siRNAs, PGF $2 \alpha$ production is decreased. They have found that the other potential PGF synthase (AKR1C3) is also 
expressed in endometrial cell cultures, but its contribution to PGF $2 \alpha$ production remains to be determined.

The endometrial release of PGF $2 \alpha$ in response to oxytocin is the initial signal triggering luteolysis in animals, and ovarian PGF2 $\alpha$ contributes to the luteolytic process in primates including humans [68]. In presence of a viable embryo, the default luteolytic signal is counteracted by an antiluteolytic or a luteotrophic signal or a combination of both to maintain the production of progesterone. PGF $2 \alpha$ is also a potent constrictor of the myometrium and uterine blood vessels [69]. In humans, PGs interact with cytokines and prolactin (PRL) to regulate decidualization and with angiogenic and coagulation factors to regulate menstruation [70]. During the menstrual cycle, the concentration of PGF2 $\alpha$ is apparently higher than PGE2 during the secretory phase, whereas levels of both PGs are low during the proliferative phase. The concentrations of PGE2 remain low, whereas PGF $2 \alpha$ goes higher during menstruation and lower during the implantation [71]. Recent reviews concur to state that across species (namely human horse pig, sheep, and cow), PGF $2 \alpha$ and PGE2 are universally important in the regulation of endometrial function $[70,72]$.

2.2. Prostaglandin F2 Receptor (PGFR). Many of uterine effects are associated with the expression and activation of prostanoid receptors, which have been derived from in vitro or in vivo studies involving the genetic or pharmacological manipulation of prostanoid receptors. Some of the known effects of prostanoid signalling include angiogenesis, proliferation, adhesion, alterations in cellular morphology, motility, invasion [33, 73], and pain perception $[74,75]$.

PGF2 $\alpha$ exerts its biological function through interactions with FP prostanoid receptors (PGFR). Reproductive tissues express different classes of prostaglandin receptors [76]. PGFR is a receptor for PGF2 $\alpha$. It is a member of the Gprotein coupled receptor family. Main effects of prostaglandin binding to the receptor are uterine (smooth muscle) contraction [77-81]. PGF $2 \alpha$ mediates luteolysis via activation of this receptor [40] and is also involved in modulating intraocular pressure and smooth muscle contraction in uterus and gastrointestinal tract sphincters. Knockout studies in mice suggest that the interaction of PGF $2 \alpha$ with this receptor in ovarian luteal cells initiates luteolysis and thus induces parturition [40].

There is evidence demonstrating that PGFR may be regulated both during pregnancy and labour, implicating its potential role in the parturition process. In rats, PGFR expression in the uterus remained low through 15-20 days of gestation, whereas at day 22 and during parturition (day 23), PGFR expression significantly increased [82-84]. In addition, mice lacking the PGFR gene remain pregnant post term [40], and administration of THG113, a PGFR antagonist, can delay preterm birth in both mice and sheep $[85,86]$. This led to the suggestion that PGFR antagonists may prove to be of benefit for the treatment of preterm labour [87].

2.3. Prostaglandin E2 Synthase (PGES). PGES is a terminal prostanoid synthase that can enzymatically convert COX product PGH2 to PGE2 [62]. PGE2 induces systemic effects and may act as a luteotrophic or antiluteolytic agent [19]. PGE2 also exerts an immunomodulation that helps to prevent rejection of the conceptus [20]. The accepted pathway for the production of PGE2 involves first the generation of PG endoperoxide $\mathrm{H} 2$ primarily through $\mathrm{COX}-2$ and then conversion into PGE2 via PGES. It has been observed that PGES may be an important rate-limiting enzyme for PGE2 biosynthesis in bovine endometrium [88].

It has been reported that recognition and establishment of pregnancy depends on the regulation of the balance between PGF $2 \alpha$ as the luteolytic signal and PGE2 as the antiluteolytic or luteotrophic signal. In this respect, the relative production of PGE2 and PGF $2 \alpha$ may be more important than the absolute production of each PG. The PGE2/PGF2 $\alpha$ ratio can be modulated in favour of PGE2 and establishment of pregnancy by three different pathways: (1) the well-accepted hypothesis of a decrease in the production of PGF $2 \alpha$; conversion of PGE2 into PGF2 $\alpha$ by a putative 9-keto-prostaglandin E2 reductase and (2) an increase in PGE2 through the stimulation of PGE synthase. Asselin et al. $[89,90]$ reported that PGE2 production is increased in both types of endometrial cells following treatment with recombinant ovine interferon tau (IFNT), a key factor for establishment of pregnancy recognition signal. In addition, IFNT silences expression of estrogen receptor alpha which prevents upregulation of oxytocin receptor (OXTR) expression, which is required for the endometrium to generate oxytocin-dependent luteolytic pulses of prostaglandin F2 $\alpha$ (PGF2 $\alpha$ ) in response to oxytocin from the $\mathrm{CL}$ and/or posterior pituitary in nonpregnant ewes. In this way, IFNT maintains CL function for continued production of progesterone, the unequivocal hormone of pregnancy that stimulates and maintains endometrial functions necessary for conceptus survival and growth in the uterus [91]. Dorniak et al. [92] supported the hypothesis that PGs synthesized and secreted by the conceptus act in paracrine alone or in concert with IFNT and progesterone to coordinately regulate endometrial functions that govern conceptus growth and elongation during the peri-implantation period of pregnancy in sheep. Therefore, PGs and IFNT from the conceptus coordinately regulate endometrial functions important. In epithelial cells, the alteration in PG production was such that the primary PG produced was changed from PGF2 $\alpha$ to PGE2. Arosh et al. [27] have shown that the expression of PGES mRNA closely followed that of COX2 during the bovine estrous cycle. Presence of PGES and its modulation under conditions known to influence PG production in bovine endometrial was reported for the first time by Parent et al. [88].

2.4. Cyclooxygenase (COX) 2. PGs are generated via the COX pathway, and COX is the rate-limiting enzyme for conversion of arachidonic acid into PGH2 [30, 93]. COX exists in to two isoforms that are encoded by two separate genes, COX1 and COX-2, which are also known as prostaglandin endoperoxide $\mathrm{H}$ synthases (PGHS)-1 and (PGHS)-2 [30]. These enzymes are responsible for the conversion of arachidonic acid into PGH2. Although COX1 is a constitutively expressed enzyme in a variety of cell types, COX-2 is the inducible enzyme 
TABLE 1: In our knowledge, status of study for mRNA expression pattern of some important genes regulating PG synthesis in different species.

\begin{tabular}{|c|c|c|c|c|c|c|c|}
\hline \multirow{2}{*}{ Name of genes } & \multicolumn{7}{|c|}{ Expression reported in endometrium of different mammalian species, across estrous/menstruation cycle (in vivo) } \\
\hline & Human & Monkey & Horse & Pig & Cow & Sheep & Goat \\
\hline AKR1B5 & $\begin{array}{c}\checkmark \\
{[53]}\end{array}$ & $\mathrm{X}$ & $\mathrm{X}$ & $\begin{array}{c}\checkmark \\
{[54]}\end{array}$ & $\begin{array}{c}\checkmark \\
{[35,55]}\end{array}$ & $\mathrm{X}$ & $\mathrm{X}$ \\
\hline PGFS/AKR1C3 & $\begin{array}{c}\checkmark \\
{[53]}\end{array}$ & $\mathrm{X}$ & $\begin{array}{c}\checkmark \\
{[56]}\end{array}$ & $\begin{array}{c}\checkmark \\
{[52,57]}\end{array}$ & $\begin{array}{c}\checkmark \\
{[55]}\end{array}$ & $\begin{array}{c}\checkmark \\
{[44]}\end{array}$ & $\mathrm{X}$ \\
\hline PGFR & $\begin{array}{c}\checkmark \\
{[58]}\end{array}$ & $\mathrm{X}$ & $\begin{array}{c}\checkmark \\
{[59]}\end{array}$ & $\mathrm{X}$ & $\begin{array}{c}\checkmark \\
{[55]}\end{array}$ & $\mathrm{X}$ & $\mathrm{X}$ \\
\hline PGES & $\begin{array}{c}\checkmark \\
{[60]}\end{array}$ & $\begin{array}{c}\checkmark \\
{[53]}\end{array}$ & $\begin{array}{c}\checkmark \\
{[56]}\end{array}$ & $\begin{array}{c}\checkmark \\
{[52,57]}\end{array}$ & $\begin{array}{c}\checkmark \\
{[27,55]}\end{array}$ & $\begin{array}{c}r \\
{[44]}\end{array}$ & $\mathrm{X}$ \\
\hline COX-2 & $\begin{array}{c}\checkmark \\
{[61]}\end{array}$ & $\begin{array}{c}\checkmark \\
{[62]}\end{array}$ & $\begin{array}{c}\checkmark \\
{[54]}\end{array}$ & $\begin{array}{c}\checkmark \\
{[28]}\end{array}$ & $\begin{array}{c}\checkmark \\
{[27,53]}\end{array}$ & $\begin{array}{c}\checkmark \\
{[13]}\end{array}$ & $\mathrm{X}$ \\
\hline
\end{tabular}

Symbol represents, reports, $\checkmark$ : available, X: not available.

that plays role in various pathological and physiological conditions in animal tissues. Although COX1 deficient female mice are fertile, they have specific defects in parturition, whereas COX-2 deficient female mice are infertile with abnormalities in ovulation, fertilization, implantation, and decidualization $[36,38,94]$. The requirement of COX-2 for normal blastocyst implantation and decidualization in mice is due to the role of COX-2-derived PGs in regulation of vascular endothelial growth factor and angiopoietin signaling that influence uterine vascular permeability and angiogenesis $[61,88,95]$. Parent et al. [32] have correlated the expression of PGES with that of COX-2, which is an important enzyme for the production of PGE2 in bovine endometrium. Increasing this production will modulate the PGE2/PGF2 $\alpha$ ratio and contribute to establishment of pregnancy.

\section{Spatiotemporal Expression of AKR1B5, AKR1C3, PGFR, PGES, and COX-2 Genes in Endometrium, across Estrus/Menstruation Cycle}

Although the ovine model has greatly advanced our understanding of how the fate of the corpus luteum is controlled, it is clear that the mechanisms involved in the maternal recognition of pregnancy vary considerably from one species to another $[17,18,96]$. Therefore, spatiotemporal expression of these genes (at transcript level) in endometrium, across estrus/menstruation cycle, was studied extensively in different species, namely, human, monkey, horse, pig, and sheep (Table 1). The reproductive pattern of the goat is rather similar to the sheep in many respects, but there are two important differences between these two species. First, the oestrous cycle length in the goat is longer (19-21 days) as compared with the sheep (16-17 days). Second, the goat relies exclusively on progesterone secreted by the CL for the maintenance of pregnancy, since the goat placenta, unlike the sheep, does not produce progesterone [17]. Despite having their significant role for the regulation of estrus cycle and maintenance of pregnancy, the above review suggested that the goat is one of the few domestic species in which these genes are still to be studied.

\section{Conclusions}

Endometrial PGs (PGF2 $\alpha$ and PGE2) synthesis, secretion and associated genes for their function, is being discussed in this review. Both PGF2 $\alpha$ and PGE2 function to establish and maintain the pregnancy by their luteolysis and luteotropic nature. The expression of these genes has been studied in various species, namely, human, monkey, horse, pig, cow, and sheep. However, in goat these genes and their expression are still to be studied. So, there is the need to explore the expression pattern of these genes in this important domestic species too. Along with these, the particular ratio of PGE2/PGF2 $\alpha$ is also unclear, which ultimately decides the microenvironment of uterus. In conclusion, the answer of these questions we left can solve the problems in reproductive performance.

\section{References}

[1] J. C. Cross, Y. Lu, M. Hemberger, and L. Adamson, "Invasion of mouse uterus by distinct trophoblast subtypes," Placenta, vol. 22, no. 7, p. 64, 2001.

[2] R. M. Roberts and T. Schalue-Francis, "Maternal recognition of pregnancy and embryonic loss," Theriogenology, vol. 33, no. 1, pp. 175-183, 1990.

[3] K. Imakawa, K. T. Chang, and R. K. Christenson, "Pre-implantation conceptus and maternal uterine communications: molecular events leading to successful implantation," Journal of Reproduction and Development, vol. 50, no. 2, pp. 155-169, 2004.

[4] S. Bauersachs, S. E. Ulbirch, K. Gross et al., "Embryo-induced transcriptome changes in bovine endometrium reveal speciesspecific and common molecular markers of uterine receptivity," Reproduction, vol. 132, no. 2, pp. 319-331, 2006.

[5] N. Forde, F. Carter, T. Fair et al., "Progesterone-regulated changes in endometrial gene expression contribute to advanced conceptus development in cattle," Biology of Reproduction, vol. 81, no. 4, pp. 784-794, 2009.

[6] N. Forde, F. Carter, T. E. Spencer et al., "Conceptus: induced changes in the endometrial transcriptome: how soon does the cow know she is pregnant?" Biology of Reproduction, vol. 85, no. 1, pp. 144-156, 2011.

[7] H. F. Chen, J. Y. Shew, H. N. Ho, W. L. Hsu, and Y. S. Yang, "Expression of leukemia inhibitory factor and its receptor in 
preimplantation embryos," Fertility and Sterility, vol. 72, no. 4, pp. 713-719, 1999.

[8] T. E. Spencer, R. C. Burghardt, G. A. Johnson, and F. W. Bazer, "Conceptus signals for establishment and maintenance of pregnancy," Reproductive Biology and Endocrinology, vol. 2, pp. 1-15, 2004.

[9] S. Katagiri and Y. Takahashi, "Changes in EGF concentrations during estrous cycle in bovine endometrium and their alterations in repeat breeder cows," Theriogenology, vol. 62, no. 1-2, pp. 103-112, 2004.

[10] S. Bauersachs, S. E. Ulbrich, K. Gross et al., "Gene expression profiling of bovine endometrium during the oestrous cycle: detection of molecular pathways involved in functional changes," Journal of Molecular Endocrinology, vol. 34, no. 3, pp. 889-908, 2005.

[11] C. Klein, S. Bauersachs, S. E. Ulbrich et al., "Monozygotic twin model reveals novel embryo-induced transcriptome changes of bovine endometrium in the preattachment period," Biology of Reproduction, vol. 74, no. 2, pp. 253-264, 2006.

[12] D. D. Michael, I. M. Alvarez, O. M. Ocón et al., "Fibroblast growth factor- 2 is expressed by the bovine uterus and stimulates interferon- $\tau$ production in bovine trophectoderm," Endocrinology, vol. 147, no. 7, pp. 3571-3579, 2006.

[13] S. Kim, Y. Choi, T. E. Spencer, and F. W. Bazer, "Effects of the estrous cycle, pregnancy and interferon tau on expression of cyclooxygenase two (COX-2) in ovine endometrium," Reproductive Biology and Endocrinology, vol. 1, article 58, 2003.

[14] L. A. Salamonsen and J. K. Findlay, "Immunocytochemical localization of prostaglandin synthase in the ovine uterus during the oestrous cycle and in early pregnancy," Reproduction, Fertility and Development, vol. 2, no. 4, pp. 311-319, 1990.

[15] G. Danet-Desnoyers, M. D. Meyer, T. S. Gross, J. W. Johnson, and W. W. Thatcher, "Regulation of endometrial prostaglandin synthesis during early pregnancy in cattle: effects of phospholipases and calcium in vitro," Prostaglandins, vol. 50, no. 5-6, pp. 313-330, 1995.

[16] E. W. Horton and N. L. Poyser, "Uterine luteolytic hormone: a physiological role for prostaglandin F2 $\alpha$," Physiological Reviews, vol. 56, no. 4, pp. 595-651, 1976.

[17] J. A. Mccracken, E. E. Custer, and J. C. Lamsa, "Luteolysis: a neuroendocrine-mediated event," Physiological Reviews, vol. 79, no. 2, pp. 263-323, 1999.

[18] J. S. Davis and B. R. Rueda, "The corpus luteum: an ovarian structure with maternal instincts and suicidal tendencies," Frontiers in Bioscience, vol. 7, pp. d1949-d1978, 2002.

[19] B. R. Pratt, R. L. Butcher, and E. K. Inskeep, "Antiluteolytic effect of the conceptus and of PGE2 in ewes," Journal of animal science, vol. 45, no. 4, pp. 784-791, 1977.

[20] P. K. Lala, "Interrruption of murine pregnancy by activation of antigen-non-specific killer cells in the endometrium with indomethacin, high dose IL-2 or a combination," Research in Immunology, vol. 141, no. 2, pp. 159-164, 1990.

[21] D. L. Davis and R. M. Blair, "Studies of uterine secretions and products of primary cultures of endometrial cells in pigs," Journal of reproduction and fertility, vol. 48, pp. 143-155, 1993.

[22] W. J. Silvia, "Eicosanoids," in Encyclopedia of Reproduction, E. Knobil and J. D. Neill, Eds., vol. 1, pp. 991-1001, Academic Press, San Diego, Calif, USA, 1998.

[23] R. N. DuBois, S. B. Abramson, L. Crofford et al., "Cyclooxygenase in biology and disease," The FASEB Journal, vol. 12, no. 12, pp. 1063-1073, 1998.
[24] C. D. Funk, "Prostaglandins and leukotrienes: advances in eicosanoid biology," Science, vol. 294, no. 5548, pp. 1871-1875, 2001.

[25] L. J. Crofford, "Prostaglandin biology," Gastroenterology Clinics of North America, vol. 30, no. 4, pp. 863-876, 2001.

[26] G. Charpigny, P. Reinaud, J. P. Tamby et al., "Expression of cyclooxygenase- 1 and -2 in ovine endometrium during the estrous cycle and early pregnancy," Endocrinology, vol. 138, no. 5, pp. 2163-2171, 1997.

[27] J. A. Arosh, J. Parent, P. Chapdelaine, J. Sirois, and M. A. Fortier, "Expression of cyclooxygenases 1 and 2 and prostaglandin E synthase in bovine endometrial tissue during the estrous cycle," Biology of Reproduction, vol. 67, no. 1, pp. 161-169, 2002.

[28] A. Blitek, A. Waclawik, M. M. Kaczmarek, T. Stadejek, Z. Pejsak, and A. J. Ziecik, "Expression of cyclooxygenase-1 and -2 in the porcine endometrium during the oestrous cycle and early pregnancy," Reproduction in Domestic Animals, vol. 41, no. 3, pp. 251-257, 2006.

[29] M. A. Fortier, K. Krishnaswamy, G. Danyod, S. P. BoucherKovalik, and J. A. Chapdelaine, "Apostgenomic integrated view of prostaglandins in reproduction: implications for other body systems," Journal of Physiology and Pharmacology, vol. 59, pp. 65-89, 2008.

[30] W. L. Smith, D. L. Dewitt, and R. M. Garavito, "Cyclooxygenases: structural, cellular, and molecular biology," Annual Review of Biochemistry, vol. 69, pp. 145-182, 2000.

[31] J. Sirois and J. S. Richards, "Purification and characterization of a novel, distinct isoform of prostaglandin endoperoxide synthase induced by human chorionic gonadotropin in granulosa cells of rat preovulatory follicles," The Journal of Biological Chemistry, vol. 267, no. 9, pp. 6382-6388, 1992.

[32] J. Parent, C. Villeneuve, and M. A. Fortier, "Evaluation of the contribution of cyclooxygenase 1 and cyclooxygenase 2 to the production of PGE2 and PGF2 $\alpha$ in epithelial cells from bovine endometrium," Reproduction, vol. 126, no. 4, pp. 539-547, 2003.

[33] K. J. Sales and H. N. Jabbour, "Cyclooxygenase enzymes and prostaglandins in reproductive tract physiology and pathology," Prostaglandins and Other Lipid Mediators, vol. 71, no. 3-4, pp. 97-117, 2003.

[34] S. K. Smith and R. W. Kelly, "The release of PGF(2 $\alpha)$ and PGE2 from separated cells of human endometrium and decidua," Prostaglandins Leukotrienes and Essential Fatty Acids, vol. 33, no. 2, pp. 91-96, 1988.

[35] E. Madore, N. Harvey, J. Parent, P. Chapdelaine, J. A. Arosh, and M. A. Fortier, "An aldose reductase with $20 \alpha$-hydroxysteroid dehydrogenase activity is most likely the enzyme responsible for the production of prostaglandin F2 $\alpha$ in the bovine endometrium," The Journal of Biological Chemistry, vol. 278, no. 13, pp. 11205-11212, 2003.

[36] R. Langenbach, S. G. Morham, H. F. Tiano et al., "Prostaglandin synthase 1 gene disruption in mice reduces arachidonic acid-induced inflammation and indomethacin-induced gastric ulceration," Cell, vol. 83, no. 3, pp. 483-492, 1995.

[37] S. G. Morham, R. Langenbach, C. D. Loftin et al., "Prostaglandin synthase 2 gene disruption causes severe renal pathology in the mouse," Cell, vol. 83, no. 3, pp. 473-482, 1995.

[38] H. Lim, B. C. Paria, S. K. Das et al., "Multiple female reproductive failures in cyclooxygenase 2-deficient mice," Cell, vol. 91, no. 2, pp. 197-208, 1997.

[39] J. V. Bonventre, Z. Huang, M. R. Taheri et al., "Reduced fertility and postischaemic brain injury in mice deficient in cytosolic phospholipase a2," Nature, vol. 390, no. 6660, pp. 622-625, 1997. 
[40] Y. Sugimoto, A. Yamasaki, E. Segi et al., "Failure of parturition in mice lacking the prostaglandin F receptor," Science, vol. 277, no. 5326, pp. 681-683, 1997.

[41] J. A. Arosh, S. K. Banu, P. Chapdelaine, E. Madore, J. Sirois, and M. A. Fortier, "Prostaglandin biosynthesis, transport, and signaling in corpus luteum: a basis for autoregulation of luteal function," Endocrinology, vol. 145, no. 5, pp. 2551-2560, 2004.

[42] T. Lindstrom and P. Bennett, "Transcriptional regulation of genes for enzymes of the prostaglandin biosynthetic pathway," Prostaglandins Leukotrienes and Essential Fatty Acids, vol. 70, no. 2, pp. 115-135, 2004.

[43] C. W. Xiao, B. D. Murphy, J. Sirois, and A. K. Goff, "Downregulation of oxytocin-induced cyclooxygenase-2 and prostaglandin F synthase expression by interferon- $\tau$ in bovine endometrial cells," Biology of Reproduction, vol. 60, no. 3, pp. 656-663, 1999.

[44] H. K. Palliser, G. T. Ooi, J. J. Hirst et al., "Changes in the expression of prostaglandin $\mathrm{E}$ and $\mathrm{F}$ synthases at induced and spontaneous labour onset in the sheep," Journal of Endocrinology, vol. 180, no. 3, pp. 469-477, 2004.

[45] K. Watanabe, R. Yoshida, T. Shimizu, and O. Hayaishi, "Enzymatic formation of prostaglandin $\mathrm{F}(2 \alpha)$ from prostaglandin $\mathrm{H} 2$ and D2. Purification and properties of prostaglandin F synthetase from bovine lung," The Journal of Biological Chemistry, vol. 260, no. 11, pp. 7035-7041, 1985.

[46] W. Kuchinke, O. Barski, K. Watanabe, and O. Hayaishi, "A lung type prostaglandin $\mathrm{F}$ synthase is expressed in bovine liver: cDNA sequence and expression in E. coli," Biochemical and Biophysical Research Communications, vol. 183, no. 3, pp. 12381246, 1992.

[47] T. Suzuki, Y. Fujii, M. Miyano, L. Y. Chen, T. Takahashi, and K. Watanabe, "cDNA cloning, expression, and mutagenesis study of liver-type prostaglandin F synthase," The Journal of Biological Chemistry, vol. 274, no. 1, pp. 241-248, 1999.

[48] L. Y. Chen, K. Watanabe, and O. Hayaishi, "Purification and characterization of prostaglandin F synthase from bovine liver," Archives of Biochemistry and Biophysics, vol. 296, no. 1, pp. 1726, 1992.

[49] T. Suzuki-Yamamoto, M. Nishizawa, M. Fukui et al., "cDNA cloning, expression and characterization of human prostaglandin F synthase," FEBS Letters, vol. 462, no. 3, pp. 335-340, 1999.

[50] W. X. Wu, X. H. Ma, T. Yoshizato, N. Shinozuka, and P. W. Nathanielsz, "Increase in prostaglandin H synthase 2, but not prostaglandin F2 $\alpha$ synthase mRNA in intrauterine tissues during betamethasone-induced premature labor and spontaneous term labor in sheep," Journal of the Society for Gynecologic Investigation, vol. 8, no. 2, pp. 69-76, 2001.

[51] B. K. Kubata, M. Duszenko, Z. Kabututu et al., "Identification of a novel prostaglandin $\mathrm{F}(2 \alpha)$ synthase in Trypanosoma brucei," Journal of Experimental Medicine, vol. 192, no. 9, pp. 1327-1337, 2000.

[52] A. Waclawik, A. Rivero-Muller, A. Blitek et al., "Molecular cloning and spatiotemporal expression of prostaglandin $\mathrm{F}$ synthase and microsomal prostaglandin E synthase-1 in porcine endometrium," Endocrinology, vol. 147, no. 1, pp. 210-221, 2006.

[53] E. Bresson, S. Boucher-Kovalik, P. Chapdelaine et al., "The human aldose reductase AKR1B1 qualifies as the primary prostaglandin F synthase in the endometrium," Journal of Clinical Endocrinology and Metabolism, vol. 96, no. 1, pp. 210219, 2011.
[54] J. W. Ross, M. D. Ashworth, F. J. White et al., "Premature estrogen exposure alters endometrial gene expression to disrupt pregnancy in the pig," Endocrinology, vol. 148, no. 10, pp. 47614773, 2007.

[55] S. E. Ulbrich, K. Schulke, A. E. Groebner et al., "Quantitative characterization of prostaglandins in the uterus of early pregnant cattle," Reproduction, vol. 138, no. 2, pp. 371-382, 2009.

[56] D. Boerboom, K. A. Brown, D. Vaillancourt et al., "Expression of key prostaglandin synthases in equine endometrium during late diestrus and early pregnancy," Biology of Reproduction, vol. 70, no. 2, pp. 391-399, 2004.

[57] M. Wasielak, K. Kamiska, and M. Bogacki, "Effect of the conceptus on uterine prostaglandin-F2 $\alpha$ and prostaglandin-E2 release and synthesis during the periimplantation period in the pig," Reproduction, Fertility and Development, vol. 21, no. 5, pp. 709-717, 2009.

[58] S. A. Milne and H. N. Jabbour, "Prostaglandin (PG) F2 $\alpha$ receptor expression and signaling in human endometrium: role of PGF $2 \alpha$ in epithelial cell proliferation," The Journal of Clinical Endocrinology \& Metabolism, vol. 88, no. 4, pp. 1825-1832, 2003.

[59] M. O. Atli, E. Kurar, S. A. Kayis et al., "Evaluation of genes involved in prostaglandin action in equine endometrium during estrous cycle and early pregnancy," Animal Reproduction Science, vol. 122, no. 1-2, pp. 124-132, 2010.

[60] S. A. Milne, G. B. Perchick, S. C. Boddy, and H. N. Jabbour, "Expression, localization, and signaling of PGE2 and EP2/EP4 receptors in human nonpregnant endometrium across the menstrual cycle," Journal of Clinical Endocrinology and Metabolism, vol. 86, no. 9, pp. 4453-4459, 2001.

[61] A. K. Matsumoto, A. Melian, D. R. Mandel et al., "A randomized, controlled, clinical trial of etoricoxib in the treatment of rheumatoid arthritis," Journal of Rheumatology, vol. 29, no. 8, pp. 1623-1630, 2002.

[62] T. Sun, S. J. Li, H. L. Diao, C. B. Teng, H. B. Wang, and Z. M. Yang, "Cyclooxygenases and prostaglandin E synthases in the endometrium of the rhesus monkey during the menstrual cycle," Reproduction, vol. 127, no. 4, pp. 465-473, 2004.

[63] K. Matsuura, H. Shiraishi, A. Hara et al., "Identification of a principal mRNA species for human $3 \alpha$-hydroxysteroid dehydrogenase isoform (AKR1C3) that exhibits high prostaglandin D2 11-ketoreductase activity," The Journal of Biochemistry, vol. 124, pp. 940-946, 1998.

[64] Y. Jin and T. M. Penning, "Aldo-keto reductases and bioactivation/detoxication," Annual Review of Pharmacology and Toxicology, vol. 47, pp. 263-292, 2007.

[65] S. K. Srivastava, K. V. Ramana, and A. Bhatnagar, "Role of aldose reductase and oxidative damage in diabetes and the consequent potential for therapeutic options," Endocrine Reviews, vol. 26, no. 3, pp. 380-392, 2005.

[66] P. Chapdelaine, J. Kang, S. Boucher-Kovalik, N. Caron, J. P. Tremblay, and M. A. Fortier, "Decidualization and maintenance of a functional prostaglandin system in human endometrial cell lines following transformation with SV40 large T antigen," Molecular Human Reproduction, vol. 12, no. 5, pp. 309-319, 2006.

[67] J. Kang, P. Chapdelaine, P. Y. Laberge, and M. A. Fortier, "Functional characterization of prostaglandin transporter and terminal prostaglandin synthases during decidualization of human endometrial stromal cells," Human Reproduction, vol. 21, no. 3, pp. 592-599, 2006.

[68] C. A. Nagle, A. F. Mendizábal, M. M. Lahoz, M. M. Porta, and M. I. Torres, "Transfer pathways between the ovaries and the uterus 
in the cebus monkeys (Cebus apella)," General and Comparative Endocrinology, vol. 144, no. 3, pp. 248-256, 2005.

[69] D. M. Olson, "The promise of prostaglandins: have they fulfilled their potential as therapeutic targets for the delay of preterm birth?" Journal of the Society for Gynecologic Investigation, vol. 12, no. 7, pp. 466-478, 2005.

[70] H. N. Jabbour, R. W. Kelly, H. M. Fraser, and H. O. D. Critchley, "Endocrine regulation of menstruation," Endocrine Reviews, vol. 27, no. 1, pp. 17-46, 2006.

[71] I. S. Fraser, "Prostaglandins, prostaglandin inhibitors and their roles in gynaecological disorders," Bailliere's Clinical Obstetrics and Gynaecology, vol. 6, no. 4, pp. 829-857, 1992.

[72] S. Narumiya and G. A. FitzGerald, "Genetic and pharmacological analysis of prostanoid receptor function," Journal of Clinical Investigation, vol. 108, no. 1, pp. 25-30, 2001.

[73] J. W. Regan, "EP2 and EP4 prostanoid receptor signaling," Life Sciences, vol. 74, no. 2-3, pp. 143-153, 2003.

[74] A. Ueno, H. Matsumoto, H. Naraba et al., "Major roles of prostanoid receptors IP and EP3 in endotoxin-induced enhancement of pain perception," Biochemical Pharmacology, vol. 62, no. 2, pp. 157-160, 2001.

[75] T. Minami, H. Nakano, T. Kobayashi et al., "Characterization of EP receptor subtypes responsible for prostaglandin E2-induced pain responses by use of EP1 and EP3 receptor knockout mice," British Journal of Pharmacology, vol. 133, no. 3, pp. 438-444, 2001.

[76] H. N. Jabbour and K. J. Sales, "Prostaglandin receptor signalling and function in human endometrial pathology," Trends in Endocrinology and Metabolism, vol. 15, no. 8, pp. 398-404, 2004.

[77] T. P. Bardin, "The role of prostaglandins in reproductive physiology," Ohio State Medical Journal, vol. 66, no. 10, pp. 10081012, 1970.

[78] C. H. Egarter and P. Husslein, "Biochemistry of myometrial contractility," Baillière's Clinical Obstetrics and Gynaecology, vol. 6, pp. 755-769, 1992.

[79] J. Senior, K. Marshall, R. Sangha, and J. K. Clayton, "In vitro characterization of prostanoid receptors on human myometrium at term pregnancy," British Journal of Pharmacology, vol. 108, no. 2, pp. 501-506, 1993.

[80] M. Abramovitz, Y. Boie, T. Nguyen et al., "Cloning and expression of a cDNA for the human prostanoid FP receptor," The Journal of Biological Chemistry, vol. 269, no. 4, pp. 2632-2636, 1994.

[81] J. H. Durn, K. M. Marshall, D. Farrar et al., "Lipidomic analysis reveals prostanoid profiles in human term pregnant myometrium," Prostaglandins, Leukotrienes and Essential Fatty Acids, vol. 82, no. 1, pp. 21-26, 2010.

[82] J. Brodt-Eppley and L. Myatt, "Changes in expression of contractile FP and relaxatory EP2 receptors in pregnant rat myometrium during late gestation, at labor, and postpartum," Biology of Reproduction, vol. 59, no. 4, pp. 878-883, 1998.

[83] Y. L. Dong and C. Yallampalli, "Pregnancy and exogenous steroid treatments modulate the expression of relaxant EP2 and contractile FP receptors in the rat uterus," Biology of Reproduction, vol. 62, no. 3, pp. 533-539, 2000.

[84] C. W. Ou, Z. Q. Chen, S. Qi, and S. J. Lye, "Expression and regulation of the messenger ribonucleic acid encoding the prostaglandin $\mathrm{F}(2 \alpha)$ receptor in the rat myometrium during pregnancy and labor," American Journal of Obstetrics and Gynecology, vol. 182, no. 4, pp. 919-925, 2000.
[85] K. G. Peri, C. Quiniou, H. Xin et al., "THG113: A novel selective FP antagonist that delays preterm labor," Seminars in Perinatology, vol. 26, no. 6, pp. 389-397, 2002.

[86] J. J. Hirst, H. C. Parkington, I. R. Young, H. K. Palliser, K. G. Peri, and D. M. Olson, "Delay of preterm birth in sheep by THG113.31, a prostaglandin F $2 \alpha$ receptor antagonist," American Journal of Obstetrics and Gynecology, vol. 193, no. 1, pp. 256-266, 2005.

[87] A. Chollet, E. Tos, and R. Cirillo, "Tocolytic effect of a selective FP receptor antagonist in rodent models reveals an innovative approach to the treatment of preterm labor," BMC Pregnancy and Childbirth, vol. 7, supplement 1, article S16, 2007.

[88] J. Parent, P. Chapdelaine, J. Sirois, and M. A. Fortier, "Expression of microsomal prostaglandin $\mathrm{E}$ synthase in bovine endometrium: coexpression with cyclooxygenase type 2 and regulation by interferon- $\tau$," Endocrinology, vol. 143, no. 8, pp. 2936-2943, 2002.

[89] E. Asselin, A. K. Goff, H. Bergeron, and M. A. Fortier, "Influence of sex steroids on the production of prostaglandins F $2 \alpha$ and E2 and response to oxytocin in cultured epithelial and stromal cells of the bovine endometrium," Biology of Reproduction, vol. 54, no. 2, pp. 371-379, 1996.

[90] E. Asselin, F. W. Bazer, and M. A. Fortier, "Recombinant ovine and bovine interferons tau regulate prostaglandin production and oxytocin response in cultured bovine endometrial cells," Biology of Reproduction, vol. 56, no. 2, pp. 402-408, 1997.

[91] F. W. Bazer, G. Wu, T. E. Spencer, G. A. Johnson, R. C. Burghardt, and K. Bayless, "Novel pathways for implantation and establishment and maintenance of pregnancy in mammals," Molecular Human Reproduction, vol. 16, no. 3, Article ID gap095, pp. 135-152, 2009.

[92] P. Dorniak, F. W. Bazer, G. Wu, and T. E. Spencer, "Conceptusderived prostaglandins regulate endometrial function in sheep," Biology of Reproduction, vol. 87, no. 1, article 9, Article ID -, pp. $1-7,2012$.

[93] T. E. Spencer and F. W. Bazer, "Ovine interferon tau suppresses transcription of the estrogen receptor and oxytocin receptor genes in the ovine endometrium," Endocrinology, vol. 137, no. 3, pp. 1144-1147, 1996.

[94] J. E. Dinchuk, B. D. Car, R. J. Focht et al., "Renal abnormalities and an altered inflammatory response in mice lacking cyclooxygenase II," Nature, vol. 378, no. 6555, pp. 406-409, 1995.

[95] H. Lim, R. A. Gupta, W. G. Ma et al., "Cyclo-oxygenase2-derived prostacyclin mediates embryo implantation in the mouse via PPAR $\delta$," Genes and Development, vol. 13, no. 12, pp. 1561-1574, 1999.

[96] A. J. Ziecik, "Old, new and the newest concepts of inhibition of luteolysis during early pregnancy in pig," Domestic Animal Endocrinology, vol. 23, no. 1-2, pp. 265-275, 2002. 

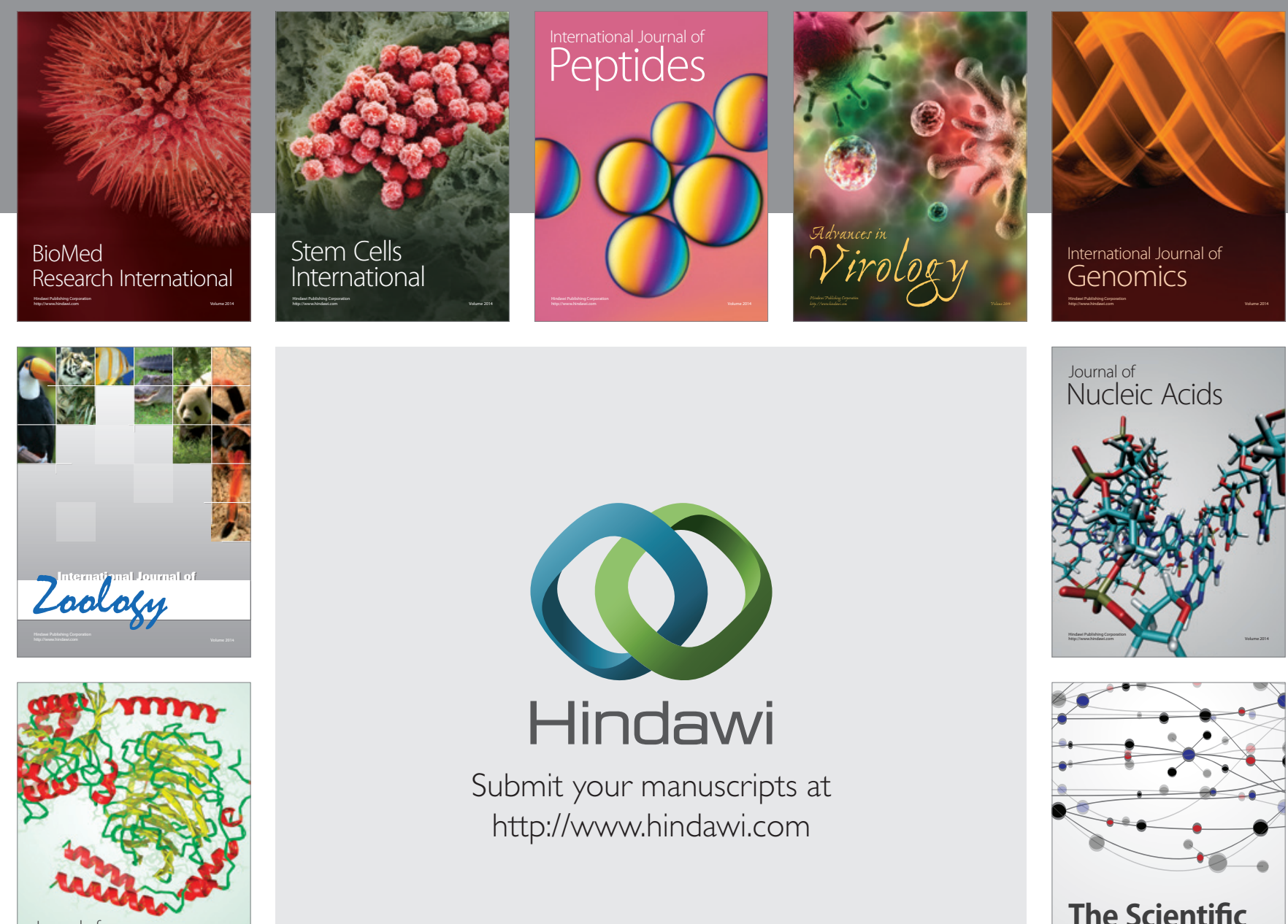

Submit your manuscripts at

http://www.hindawi.com

Journal of
Signal Transduction
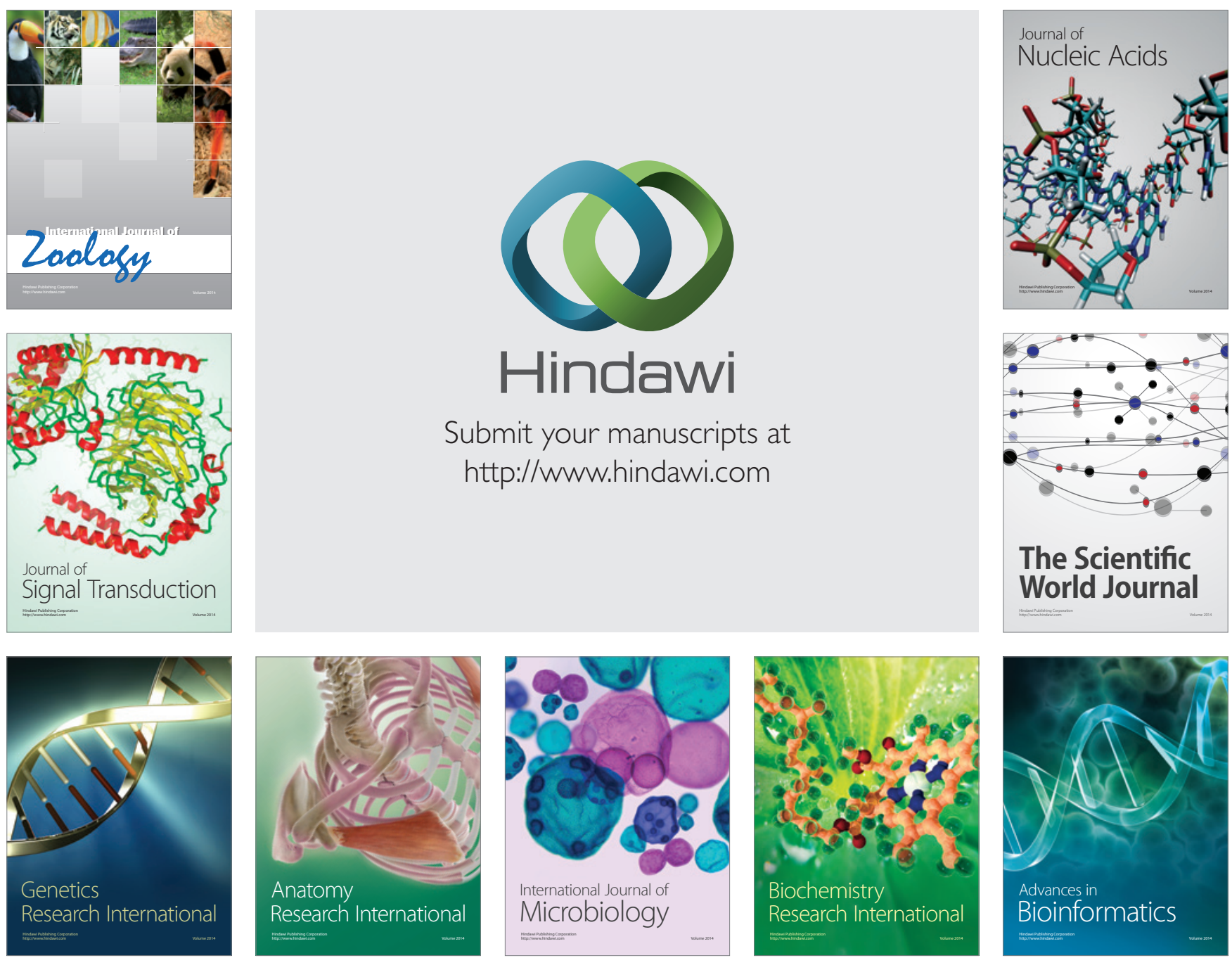

The Scientific World Journal
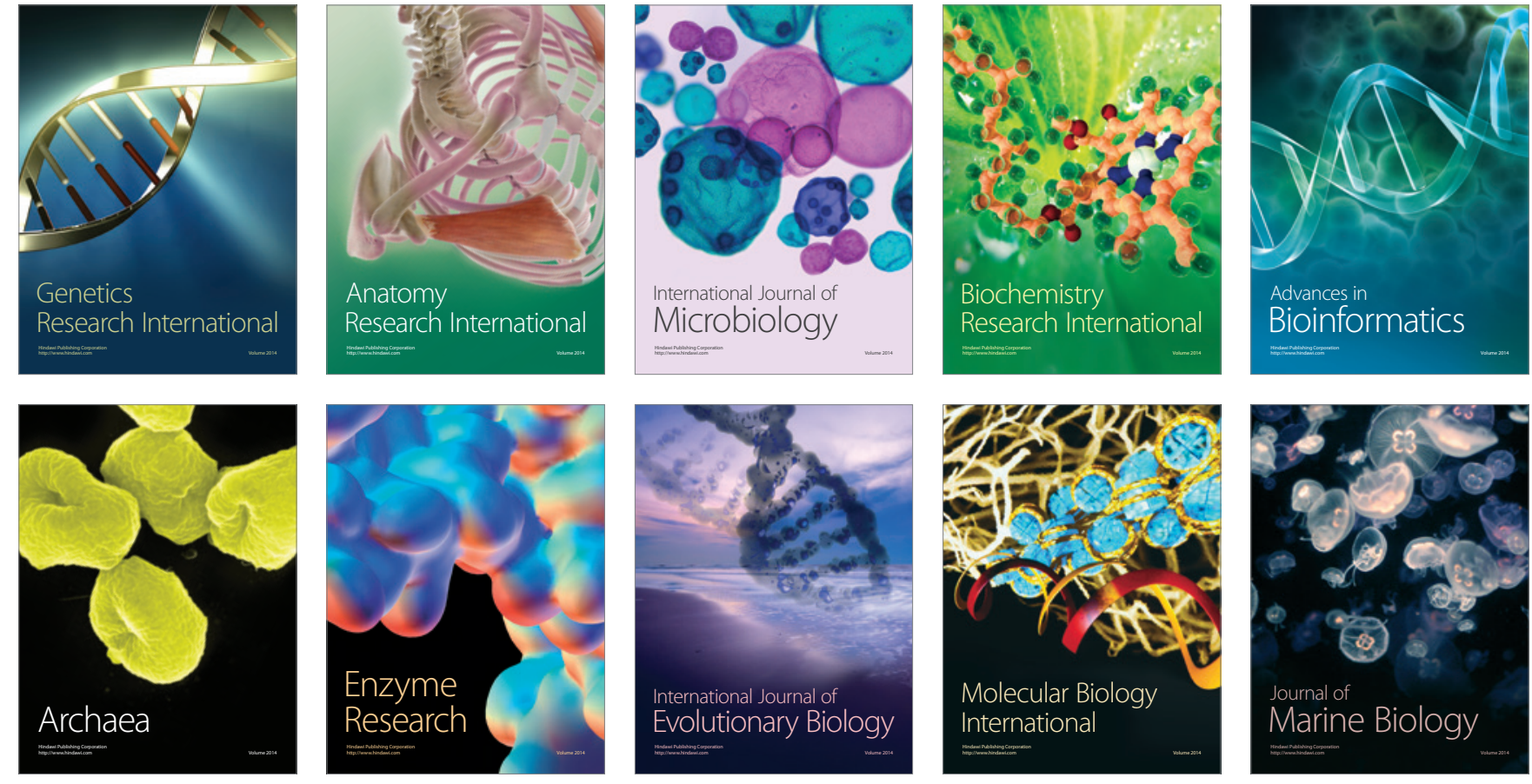